\title{
One- or Two- Levels Treatment by Arthroplasty of Cervical Degenerative Disease. Preliminary Results after 5 Years Postoperative Controls
}

Fransen $\mathbf{P}^{1^{*}}$, Noriega $\mathbf{D}^{2}$, Chatzisotiriou $\mathbf{A}^{3}$ and Pointillart $\mathbf{V}^{4}$

${ }^{1}$ Medical-Orthopedic Surgical Clinic, Principality of Monaco

2 University Clinical Hospital of Valladolid (HCU), Valladolid, Spain

${ }^{3}$ St Luc Clinic, Thessaloniki, Greece

${ }^{4}$ Hospital Pellegrin Bordeaux, Bordeaux, France

*Corresponding author: Fransen P, Medical-Orthopedic Surgical Clinic, 10 Avenue d'Ostende, 98000 Monaco, Principality of Monaco, Tel: +377 9999 1000; E-mail: fransenp@yahoo.fr

Rec Date: December 13, 2017; Acc Date: January 01, 2018; Pub Date: January 06, 2018

Copyright: (c) 2018 Fransen P, et al. This is an open-access article distributed under the terms of the creative commons attribution license, which permits unrestricted use, distribution, and reproduction in any medium, provided the original author and source are credited.

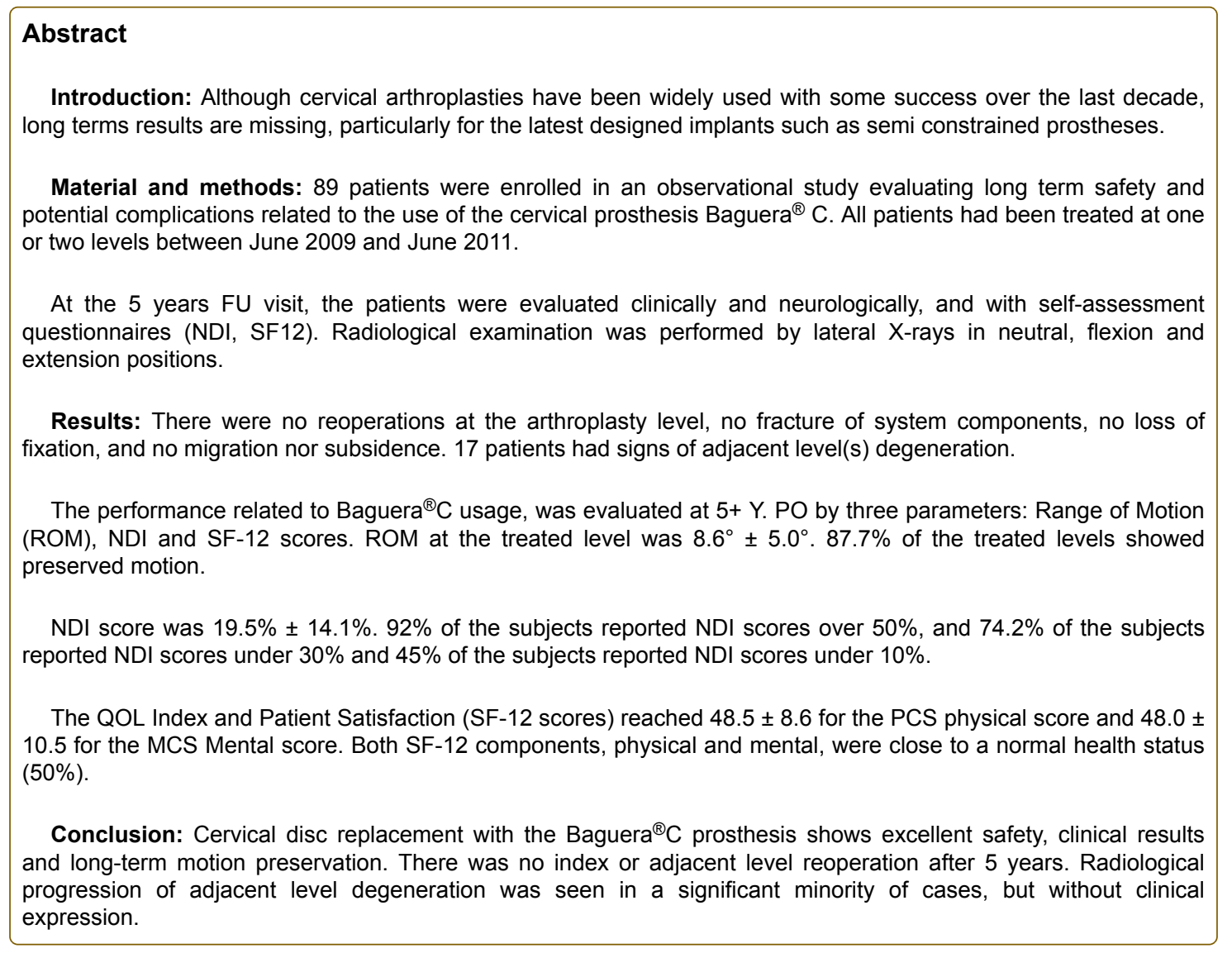

Keywords: Cervical disc replacement; Motion preservation; Cervical disc disease

\section{Introduction}

Cervical total disc replacement with disc prostheses has been widely used over the last decade and has shown promising short-term results. However, although the selection criteria to find the adequate candidates for this surgery have improved over the years [1-3], long term results have long been missing particularly for the latest designed implants such as semi constrained prostheses. This could explain why anterior cervical discectomy and fusion procedure is still considered as standard of care for $84.3 \%$ of the surgeons compared to only $7.3 \%$ for arthroplasty [4].

We evaluated the long-term safety, potential late complications and long-term performance related to the use of the cervical prosthesis Baguera $\mathrm{C}^{*}$, a semi constrained cervical disc prosthesis (Spineart Inc, Switzerland) in an observational multicentric study.

\section{Materials and Methods}

89 patients ( 45 men, 44 women, aged $44.9 \pm 6.9$ years at the time of surgery) were operated using total disc replacement at one or two cervical levels between June 2009 and June 2011, in four different 
Citation: Fransen P, Noriega D, Chatzisotiriou A, Pointillart V (2018) One- or Two- Levels Treatment by Arthroplasty of Cervical Degenerative Disease. Preliminary Results after 5 Years Postoperative Controls. J Spine 7: 405. doi:10.4172/2165-7939.1000405

Page 2 of 5

European surgical centres. A total of 109 prostheses were implanted, 52 in C5C6 (47.7\%), 39 in C6C7 (35.8\%), 15 in C4C5 (13.8\%) and 3 in C3C4 (2.8\%) (Table 1).

\begin{tabular}{|c|c|c|c|c|}
\hline \multirow{2}{*}{ Parameters } & \multicolumn{4}{|c|}{ Postoperative controls } \\
\cline { 2 - 5 } & \multicolumn{2}{|c|}{ 2Y } & \multicolumn{2}{|c|}{$5+$ Y } \\
\hline Subjects (Overall) & N & $\%$ & N & $\%$ \\
\hline Female & 64 & $54.20 \%$ & 44 & $49.40 \%$ \\
\hline Male & 54 & $45.80 \%$ & 45 & $50.60 \%$ \\
\hline Age (years, at the surgery time) & 118 & $43.8 \pm 8.9$ & 89 & $44.9 \pm 6.9$ \\
\hline Baguera®C IMPLANTED & \multicolumn{2}{|c|}{149} & \multicolumn{2}{|c|}{109} \\
\hline Surgery details & N & $\%$ & N & $\%$ \\
\hline TDR (overall) & 98 & $83.10 \%$ & 70 & $78.70 \%$ \\
\hline TDR 1 level & 70 & $59.30 \%$ & 50 & $56.20 \%$ \\
\hline TDR 2 levels & 25 & $21.20 \%$ & 20 & $22.50 \%$ \\
\hline TDR 3 levels & 3 & $0.80 \%$ & - & - \\
\hline Hybrid surgery & 20 & $16.90 \%$ & 19 & $21.30 \%$ \\
\hline Follow-up duration (years) & & $6.3 \pm 0.6$ \\
\hline
\end{tabular}

Table 1: Demography, surgery details and follow-up duration.

The Baguera $\mathrm{C}$ cervical prosthesis is composed of inferior and inferior titanium endplates, and of a high-density polyethylene (PE) guided semi-mobile nucleus inserted in the inferior endplate. The PE is in contact with the endplates through a diamond like carbon coating. Its stability is obtained by both fins and anatomical shape. It allows a mobility of $8^{\circ}$ of arc in all directions.

All patients were available for the extended follow-up, according to the protocol, and had signed the informed consent for use of their data. Safety was assessed by the rate of surgical revision at the treated level, explanation, fracture of the system, migration and local neurological, vertebral or vascular complications.

At the 5 years follow up visit, the patients were assessed by clinical and neurological examination, Neck Disability Index (NDI) questionnaire and SF 12 self-assessment questionnaire. The radiological examination was done using plain standard lateral cervical $\mathrm{X}$-ray images, performed in neutral, flexion and extension positions allowing measurements of range of motion angle (ROM).

The case report file was completed at each patient control visit, safety data were collected continuously, during the overall study period, using adverse events forms. Complications were reported in specific forms. This study was conducted according to the ISO 14155:2011 standard, to national regulations applicable in the participating countries and in agreement to the Good Clinical Practices guidelines.

\section{Results and Discussion}

There were no cases of surgical reoperation at the arthroplasty level, no fracture of system components, no loss of fixation, and nor any migration or subsidence. No vascular injury, neurological complications or vertebral fractures were reported. 17 patients had radiological signs of adjacent level(s) degeneration. Four patients needed surgical intervention at another spinal (non-cervical) level (Table 2).

\begin{tabular}{|c|c|c|c|c|}
\hline \multirow[t]{2}{*}{ Parameters } & \multicolumn{4}{|c|}{ Postoperative controls } \\
\hline & \multicolumn{2}{|c|}{$2 Y$} & \multicolumn{2}{|c|}{$5+Y$} \\
\hline \multicolumn{5}{|c|}{ Heterotopic ossifications } \\
\hline Grade 0 (No HO) & 46 & $46.10 \%$ & - & - \\
\hline Grade I, II & 34 & $34.60 \%$ & - & - \\
\hline Grade III, IV & 19 & $19.30 \%$ & - & - \\
\hline \multicolumn{5}{|c|}{ Complications } \\
\hline $\begin{array}{l}\text { Surgical revision at the index level/ Ex- } \\
\text { plantation (Removal) }\end{array}$ & 0 & $0 \%$ & 0 & $0 \%$ \\
\hline Surgery at the adjacent level & 0 & $0 \%$ & 0 & $0 \%$ \\
\hline Loss of fixation, Migration & 0 & $0 \%$ & 0 & $0 \%$ \\
\hline Subsidence & 0 & $0 \%$ & 0 & $0 \%$ \\
\hline \multicolumn{5}{|c|}{ Neurologic functions } \\
\hline Motor functions & 113 & - & - & - \\
\hline Degradation & 0 & $0 \%$ & - & - \\
\hline Stable or improved & 113 & $100 \%$ & & -- \\
\hline Reflexes & 113 & - & - & - \\
\hline Degradation & 0 & $0 \%$ & - & - \\
\hline Stable or improved & 113 & $100 \%$ & - & - \\
\hline Sensitivity & 113 & - & - & - \\
\hline Degradation & 1 & $0.90 \%$ & - & - \\
\hline Stable or improved & 112 & $99.10 \%$ & - & - \\
\hline Neurological or vascular disorders & - & - & 2 & $2.20 \%$ \\
\hline Adjacent level degeneration & - & - & 17 & $\begin{array}{c}19.10 \\
\%\end{array}$ \\
\hline Serious complications (rate) & 0 & $0 \%$ & 0 & $0 \%$ \\
\hline
\end{tabular}

Table 2: Baguera ${ }^{\circ} \mathrm{C}$ safety parameters at 2 and 5 years postoperatively.

69 patients (77.6\%) took no pain medication at all and 15 patients (16.9\%) took Level 1 painkillers (frequently for two of them). Two patients took respectively Level $2(2.2 \%)$ painkillers and two others Level $3(2.2 \%)$ painkillers. One subject took homeopathic medication (1.1\%). All subjects had normal clinical examinations. Neurological examination was normal in all but one patient who developed progressive new symptoms of C6 paraesthesia, possibly related to adjacent level degeneration.

The NDI questionnaires show an average functional disability of $19.5 \% \pm 14.1 \%$. 44 subjects $(45 \%)$ noted 0 to $10 \%$ functional disability; 7 subjects $(7.9 \%)$ noted at least $50 \%$ to $62 \%$ functional disability (Table $3)$. 
Citation: Fransen P, Noriega D, Chatzisotiriou A, Pointillart V (2018) One- or Two- Levels Treatment by Arthroplasty of Cervical Degenerative Disease. Preliminary Results after 5 Years Postoperative Controls. J Spine 7: 405. doi:10.4172/2165-7939.1000405

Page 3 of 5

\begin{tabular}{|c|c|c|c|c|}
\hline \multirow{2}{*}{ Parameters } & \multicolumn{4}{|c|}{ Postoperative controls } \\
\cline { 2 - 5 } & \multicolumn{2}{|c|}{ 2Y } & \multicolumn{2}{c|}{$\mathbf{5 + Y}$} \\
\hline NDI scores (\%) & N (subjects) & Mean & N (subjects) & Mean \pm SD \\
\hline Overall & 113 & $19.7 \pm 14.0$ & 89 & $19.5 \pm 14.1$ \\
\hline TDR 1 level & 67 & $19.0 \pm 16.2$ & 50 & $17.2 \pm 13.9$ \\
\hline TDR 2 levels & 24 & $13.6 \pm 14.2$ & 20 & $20.1 \pm 17.1$ \\
\hline TDR 3 levels & 3 & $35.3 \pm 23.4$ & - & - \\
\hline Hybrid surgery & 19 & $27.1 \pm 15.1$ & 19 & $24.9 \pm 11.0$ \\
\hline Pain medication (PM) & - & N (subjects) & $\%$ \\
\hline No PM & - & - & 69 & $77.50 \%$ \\
\hline Level 1 PM & - & - & 15 & $16.90 \%$ \\
\hline Level 2 and 3 PM & - & - & 4 & $4.40 \%$ \\
\hline Homeopatic & - & - & 1 & $1.10 \%$ \\
\hline
\end{tabular}

Table 3: Functional disability (NDI scores) and pain medications at 2 and $5+$ years postoperatively.

The SF-12 scores were calculated after $5+$ year controls for all 89 subjects using the Quality Metric SF-12V2 software. The PCS-12 and MCS- 12 values, respectively of $48.53 \%$ and $48.01 \%$ are close to normal health. Vitality scores are slightly superior to normal health (50\%). All other parameters are higher than $46 \%$ (Figure 1 ).

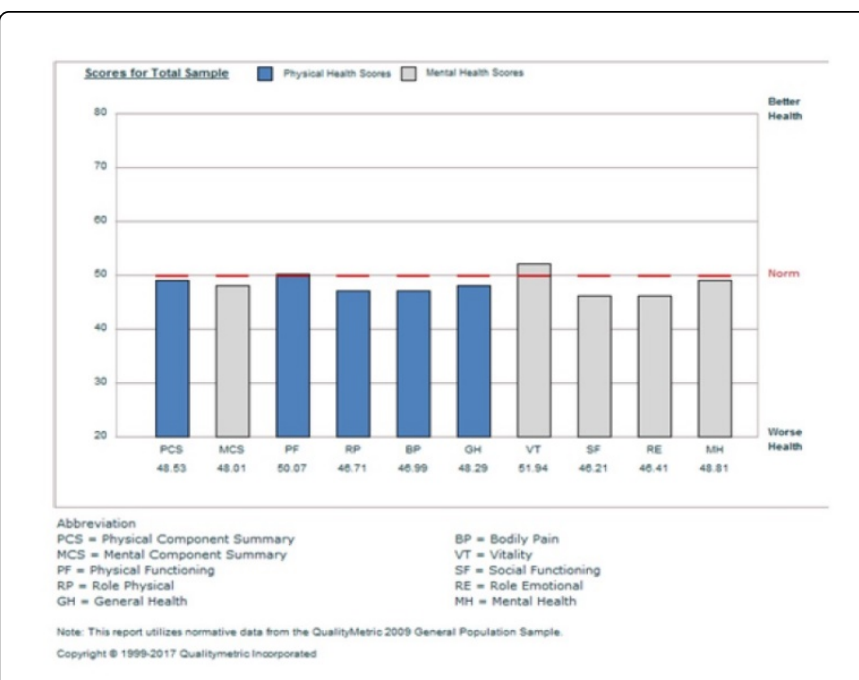

Figure 1: Normative data from the Quality Metric 2009 general population sample.

The motion at the treated level was evaluated by the range of motion for 106 cervical levels using flexion/extension X-rays. ROM data was missing for 3 treated levels, due to poor image quality.

The average ROM at the treated level was $8.6^{\circ} \pm 5^{\circ}$. Motion was considered preserved $\left(\mathrm{ROM} \geq 2^{\circ}\right)$ in 93 levels $(87.7 \%)$ (Figure 2). Lack of motion $\left(\mathrm{ROM}<2^{\circ}\right)$ was observed in 13 levels $(12.3 \%)$. (Table 4$)$

\begin{tabular}{|c|c|c|c|c|}
\hline \multirow{3}{*}{$\begin{array}{c}\text { Parameters } \\
\text { ROM (at the index level) }\end{array}$} & \multicolumn{4}{|c|}{ Postoperative controls } \\
\hline & \multicolumn{2}{|c|}{$2 Y$} & \multicolumn{2}{|c|}{$5+Y$} \\
\hline & $\begin{array}{c}\mathrm{N} \\
\text { (levels) }\end{array}$ & Degree & $\stackrel{\mathrm{N}}{\text { (levels) }}$ & Degree \\
\hline Overall & - & - & 106 & $8.6^{\circ} \pm 5.0^{\circ}$ \\
\hline TDR 1 level & 45 & $8.8^{\circ} \pm 4.6^{\circ}$ & 49 & $8.0^{\circ} \pm 5.2^{\circ}$ \\
\hline TDR 2 levels & 27 & $9.2^{\circ} \pm 5.3^{\circ}$ & 38 & $9.3^{\circ} \pm 4.5^{\circ}$ \\
\hline Hybrid surgery & 15 & $7.8^{\circ} \pm 0.4^{\circ}$ & 19 & $8.6^{\circ} \pm 5.1^{\circ}$ \\
\hline ROM (at the upper level) & $\begin{array}{c}\mathrm{N} \\
\text { (levels) }\end{array}$ & Degree & $\begin{array}{c}\mathrm{N} \\
\text { (levels) }\end{array}$ & Degree \\
\hline TDR 1 level & 55 & $13.5^{\circ} \pm 5.4^{\circ}$ & - & - \\
\hline TDR 2 levels & 33 & $10.9^{\circ} \pm 5.1^{\circ}$ & - & - \\
\hline Hybrid surgery & 5 & $7.2^{\circ} \pm 3.7^{\circ}$ & - & - \\
\hline MOTION (at the index level) & $\begin{array}{c}\mathrm{N} \\
\text { (levels) }\end{array}$ & $\%$ & $\stackrel{\mathrm{N}}{\text { (levels) }}$ & $\%$ \\
\hline Preserved $\left(\mathrm{ROM}>2^{\circ}\right)$ & 87 & $91.60 \%$ & 93 & $87.70 \%$ \\
\hline Lack of Motion $\left(\mathrm{ROM}<2^{\circ}\right)$ & 8 & $8.40 \%$ & 13 & $12.30 \%$ \\
\hline
\end{tabular}

Table 4: Motion at the arthroplasty (TDR) level and upper adjacent level at 2 and $5+$ years postoperatively.

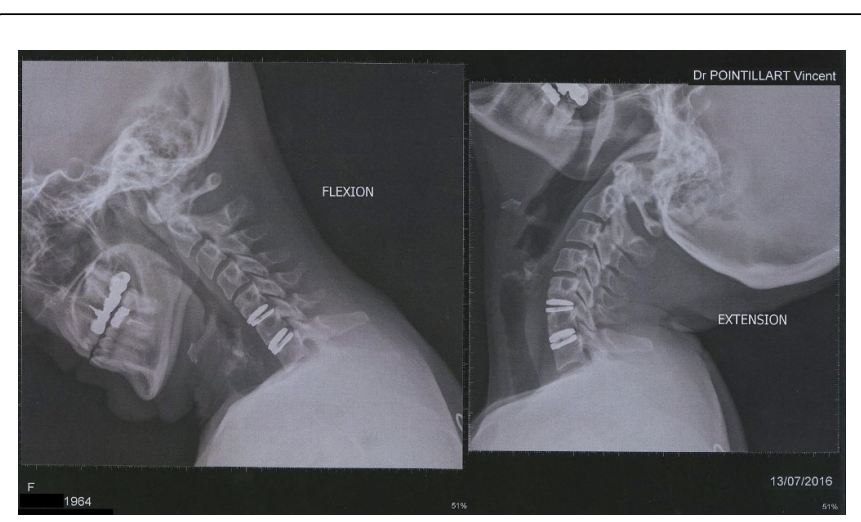

Figure 2: Lateral cervical X-ray, in flexion and extension showing motion at the operated levels after 5 years follow-up.

11 cases of mild anterior bone loss were observed, appearing as a blunting of the anterior corner of the vertebral bone, with no correlation to specific clinical symptoms, stable or completely reconstructed after 2 years postoperative controls.

\section{Discussion}

Although long term studies regarding cervical arthroplasties are not numerous, several randomized controlled trials have been published. Despite the fact that most of these RCT's were so called "industry driven", all were accepted by the American Food and Drug Administration that used very strict criteria to determine noninferiority and superiority [5-13]. 
In the Turel et al. meta-analysis of all these FDA approved artificial cervical discs [14], all implants scored either superior or non-inferior to anterior cervical discectomy and fusion. Curiously, depending on the type of arthroplasty implant, different prosthesis scored differently, some showing superiority for NDI, some for secondary surgery, some for neurological success. The reason for these differences is unclear, but could be the consequence of differences in design, materials, surgical technique and biomechanics. It is fair to conclude that different prosthesis should be evaluated separately.

The longest available follow up has reached 10 years for 97 patients implanted with the Bryan cervical prosthesis by the Leuven group [15]. The prostheses were able to maintain motion at index level and more motion was associated with less degeneration over time at the level cranial to the prosthesis.

Despite these reports, the cost effectiveness of cervical arthroplasty remains a much-debated topic. In his study, Qureshi et al showed that both arthroplasty and anterior fusion were cost effective procedures [16], and that for arthroplasty to be more cost effective than fusion, artificial discs had to stay mobile for 14 years. Although this calculation is partially depending on and negatively impacted by the price of the implant, a low number of complications and reoperations for arthroplasty would certainly increase the attractivity of this procedure.

With a negligible rate of complications and reoperations, our study confirms on a much smaller scale, the results of the American College of Surgeons Database analysis, in which, Bhashyam et al reported a lower rate of reoperation and readmission for cervical arthroplasty (both $0.4 \%$ ) than for ACDF (respectively $2.6 \%$ readmission and $1.2 \%$ reoperation) [17].

Our study group previously published favourable results with a two year follow up of a group of patients treated with the same device, reporting cervical mobility preservation in $80.6 \%$ of the patients, an $\mathrm{HO}$ rate of $54 \%$, mostly grade I and II, no signs of subsidence and no signs of degeneration or kyphosis of the adjacent disc [18]. Clinically, after two years, there was an improvement of over $20 \%$ of the NDI in $81.8 \%$ of the patients, of over $20 \%$ of the neck pain in $75.5 \%$ and of $20 \%$ in arm pain in $77.6 \%$ [19].

The analysis of these 5 years follow-up results confirms the two-year results, with overall preservation of the ROM, and favorable NDI scores, and no reoperations. Despite this, $20.5 \%$ of the patients still take occasional level 1 painkillers, raising questions about the cause of these pains: Can they be qualified as chronic pain? Are they related to adjacent level degeneration of is it just caused by normal ageing and not significant? Burkhardt et al reported in a 28 years FU of ACDF patients, that $18 \%$ of them were still occasionally taking mild pain killers [20]. Our observation could reflect similar neck sensitivity in some patients. Compared to other published long term follow up studies, our data show superior or equivalent results, with regard to motion at the treated level, functional disability and health related quality of life questionnaires [21-27].

Our anterior bone loss observations could not be correlated to clinical symptoms, and may be the result of bone remodelling consecutive to the motion preservation effect of the operated cervical segment. In a similar observation with the same prosthesis. Heo et al. hypothesized that anterior bone loss may be associated with a higher level of physical activity [28].
These first results with the Baguera $\mathrm{C}$ prosthesis at 5 years $\mathrm{FU}$ add a brick to an already robust wall of evidence supporting that cervical arthroplasty in the right indications lowers the risk for reoperation, decreases the risk of adjacent level degeneration and comes with a minimal rate of adverse events. As an even longer follow-up will possibly answer more questions, all patients included in this analysis remain under continuous monitoring, with yearly check-up, until their 10 years post-surgery visit.

\section{Conclusion}

Cervical disc replacement with the Baguera $\mathrm{C}$ prosthesis shows an excellent record in terms of safety, clinical results and long-term motion preservation. There was no index or adjacent level reoperation after 5 years. Radiological progression of adjacent level degeneration was seen in a significant minority of cases, but without clinical expression.

\section{References}

1. Depreitere B, Fransen P, Goffin J, Lubansu A, Put E, et al. (2009) Recommendations of good practice for cervical disc replacement Surgical Neurology 71: 138 .

2. Fransen P, Pointillart V (2016) Arthroplasty with the Baguera ${ }^{\oplus} \mathrm{C}$ cervical disc prosthesis: Review of the scientific background, clinical and radiographic evidences. J Spine Neurosurg 5: 6.

3. Joaquim AF, Riew KD (2017) Multilevel cervical arthroplasty: current evidence. A systematic review. Neurosurg Focus 42: E4.

4. Chin-See-Chong TC, Gadjradj PS, Boelen RJ, Harhangi BS (2017) Current practice of cervical disc arthroplasty: A survey among 383 AOSpine International members. Neurosurg Focus 42: E8.

5. Burkus JK, Haid RW, Traynelis VC, Mummaneni PV (2010) Long-term clinical and radiographic outcomes of cervical disc replacement with the Prestige disc: Results from a prospective randomized controlled clinical trial. J Neurosurg Spine 13: 308-318.

6. Coric D, Nunley PD, Guyer RD, Musante D, Carmody CN, et al. (2011) Prospective, randomized, multicenter study of cervical arthroplasty: 269 patients from the Kineflex $\mid \mathrm{C}$ artificial disc investigational device exemption study with a minimum 2-year follow-up: clinical article. J Neurosurg Spine 15: 348-358.

7. Coric D, Mummaneni PV, Traynelis V, Wang J (2017) Introduction: Cervical arthroplasty. Neurosurg Focus 42: E1.

8. Davis RJ, Kim KD, Hisey MS, Hoffman GA, Bae HW, et al. (2013) Cervical total disc replacement with the Mobi-C cervical artificial disc compared with anterior discectomy and fusion for treatment of 2-level symptomatic degenerative disc disease: A prospective, randomized, controlled multicenter clinical trial: clinical article. J Neurosurg Spine 19: 532-545.

9. Heller JG, Sasso RC, Papadopoulos SM, Anderson PA, Fessler RG, et al. (2009) Comparison of BRYAN cervical disc arthroplasty with anterior cervical decompression and fusion: clinical and radiographic results of a randomized, controlled, clinical trial. Spine 34: 101-107.

10. Mummaneni PV, Burkus JK, Haid RW, Traynelis VC, Zdeblick TA (2007) Clinical and radiographic analysis of cervical disc arthroplasty compared with allograft fusion: a randomized controlled clinical trial. J Neurosurg Spine 6: 198-209.

11. Murrey D, Janssen M, Delamarter R, Goldstein J, Zigler J, et al. (2009) Results of the prospective, randomized, controlled multicenter Food and Drug Administration investigational device exemption study of the ProDisc-C total disc replacement versus anterior discectomy and fusion for the treatment of 1-level symptomatic cervical disc disease. Spine J 9: 275-286.

12. Phillips FM, Lee JY, Geisler FH, Cappuccino A, Chaput CD, et al. (2013) A prospective, randomized, controlled clinical investigation comparing PCM cervical disc arthroplasty with anterior cervical discectomy and 
Citation: Fransen P, Noriega D, Chatzisotiriou A, Pointillart V (2018) One- or Two- Levels Treatment by Arthroplasty of Cervical Degenerative Disease. Preliminary Results after 5 Years Postoperative Controls. J Spine 7: 405. doi:10.4172/2165-7939.1000405

Page 5 of 5

fusion. 2-year results from the US FDA IDE clinical trial. Spine 38: E907E918.

13. Vaccaro A, Beutler W, Peppelman W, Marzluff JM, Highsmith J, et al. (2013) Clinical outcomes with selectively constrained SECURE-C cervical disc arthroplasty: Two-year results from a prospective, randomized, controlled, multicenter investigational device exemption study. Spine 38 2227-2239.

14. Turel MK, Kerolus MG, Adogwa O, Traynelis VC (2017) Cervical arthroplasty: What does the labeling say?. Neurosurg Focus 42: E2.

15. Dejaegher J, Walraevens J, Van Loon J, Van Calenbergh F, Demaerel P, et al. (2017)10-year follow-up after implantation of the Bryan Cervical Disc Prosthesis. Eur Spine J 26: 1191-1198.

16. Qureshi SA, McAnany S, Goz V, Koehler SM, Hecht AC (2013) Costeffectiveness analysis: comparing single-level cervical disc replacement and single-level anterior cervical discectomy and fusion: Clinical article. J Neurosurg Spine 19: 546-554.

17. Bhashyam N, De la Garza Ramos R, Nakhla J, Nasser R, Jada A, et al. (2017) Thirty-day readmission and reoperation rates after single-level anterior cervical discectomy and fusion versus those after cervical disc replacement. Neurosurg Focus 42: E6.

18. Fransen P, Hansen-Algenstaedt N, Chatzisotiriou A, Gonzalez Noriega DC, Verheyden J, et al. (2016) Radiographic outcome and adjacent segment evaluation two years after cervical disc replacement with the baguera ${ }^{\circ} \mathrm{c}$ prosthesis as treatment of degenerative cervical disc disease. J Spine 5: 298.

19. Fransen P, Hansen-Algenstaedt N, Chatzisotiriou A, Gonzalez Noriega DC, Pointillart V (2016) Clinical results of cervical disc replacement with the Baguera $C$ prosthesis after two years follow-up. Acta Orthop Belg

20. Burkhardt BW, Brielmaier M, Schwerdtfeger K, Oertel JM (2017) Clinical outcome following anterior cervical discectomy and fusion with and without anterior cervical plating for the treatment of cervical disc herniation-a 25-year follow-up study. Neurosurg Rev 1-10.
21. Bae HW, Kim KD, Nunley PD, Jackson RJ, Hisey MS, et al. (2015) Comparison of clinical outcomes of 1- and 2-level total disc replacement: Four-year results from a prospective, randomized, controlled, multicenter ide clinical trial. Spine 40: 759-766.

22. Hisey MS, Bae HW, Davis RJ, Gaede S, Hoffman G, et al. (2015) Prospective, randomized comparison of cervical total disk replacement versus anterior cervical fusion: Results at 48 months follow-up. J Spinal Disord Tech 28: E237-E243.

23. Janssen ME, Zigler JE, Spivak JM, Delamarter RB, Darden BV, et al. (2015) ProDisc-C total disc replacement versus anterior cervical discectomy and fusion for single-level symptomatic cervical disc disease: Seven-year follow-up of the prospective randomized U.S. food and drug administration investigational device exemption study. J Bone Joint Surg Am 97: 1738-1747.

24. Malham GM, Parker RM, Ellis NJ, Chan PG, Varma D (2014) Cervical artificial disc replacement with ProDisc-C: clinical and radiographic outcomes with long-term follow-up. J Clin Neurosci 21: 949-953.

25. Phillips FM, Geisler FH, Gilder KM, Reah C, Howell KM, et al. (2015) Long-term outcomes of the us fda ide prospective, randomized controlled clinical trial comparing $\mathrm{pcm}$ cervical disc arthroplasty with anterior cervical discectomy and fusion. Spine 40: 674-683.

26. Skeppholm M, Svedmark P, Noz ME, Maguire GQ Jr, Olivecrona H, et al. (2015) Evaluation of mobility and stability in the Discover artificial disc: An in vivo motion study using high-accuracy 3D CT data. J Neurosurg Spine 23: 383-389.

27. Zigler JE, Delamarter R, Murrey D, Spivak J, Janssen M (2013) ProDisc-C and anterior cervical discectomy and fusion as surgical treatment for single-level cervical symptomatic degenerative disc disease: five-year results of a Food and Drug Administration study. Spine 38: 203-209.

28. Heo DH, Lee DC, Oh JY, Park CK (2017) Bone loss of vertebral bodies at the operative segment after cervical arthroplasty: A potential complication?. Neurosurg Focus 42: E7. 